\title{
LA NOVELA HISTÓRICA ESPAÑOLA EN LA TRANSICIÓN Y EN LA DEMOCRACIA
}

\author{
Mar LANGA PIZARRO \\ U. I. de Literatura Hispanoamericana (Universidad de Alicante)
}

Hace treinta años de la muerte de Franco, y veinte de la eclosión de lo que se llamó «la nueva narrativa española», epígrafe bajo el que se pretendía agrupar a un grupo llamativamente nutrido de escritores que habían optado por la prosa de ficción, y estaban obteniendo el favor del público y de buena parte de la critica. El paso del tiempo ha permitido formular algunas características de la narrativa de este periodo: la proliferación de cuentos y novelas cortas, la recuperación del placer de contar historias, la simplificación de estructuras, la diversidad de temas y estilos, el individualismo, y la presencia de protagonistas insatisfechos.

Además, parece certificado el declive de la novela experimental (que, sin embargo, ha seguido teniendo cultivadores como Miguel Espinosa, Juan Benet, Julián Ríos y Aliocha Coll), frente al auge de la novela de género, fundamentalmente la policiaca (con el magisterio de Manuel Vázquez Montalbán, y nombres consolidados como Eduardo Mendoza, Juan Madrid y Andreu Martín) y la de tema histórico (cultivada por veteranos como Gonzalo Torrente Ballester y Jesús Fernández Santos, y por narradores más jóvenes, como Julio Llamazares, Antonio Muñoz Molina y Lourdes Ortiz).

En muchas ocasiones, no obstante, se trata de géneros impuros, en que los rasgos de una determinada tendencia se ven mezclados con los de otra: encontramos narraciones en las que confluyen temas y recursos de la novela histórica, policiaca y de aventuras (Arturo Pérez Reverte, Matilde Asensi), creaciones culturalistas con evocaciones históricas (Antonio Colinas, Jesús Ferrero, Javier Marías), trazos líricos e intimistas en el relato de hechos pasados (Julio Llamazares). his- 
toria embutida en el memorialismo (Jorge Semprún)... De cualquier modo, la vertiente histórica, en sus más diversas expresiones (pura o impura; de la intrahistoria o propiamente histórica; tradicional o innovadora), ha sido una de las más cultivadas y de las mejor acogidas de la narrativa española desde 1975. Por eso, no es ocioso acercarnos a la evolución de la «novela histórica», antes de centrarnos en algunos de sus representantes actuales.

\section{Historia del género}

Llamamos novela histórica a aquella que trata de reproducir de modo verosímil una determinada época del pasado, preferentemente no vivida por el autor. Para ello, conjuga lo real y lo inventado, las técnicas historiográficas y las novelescas. Del peso que tengan los asuntos históricos y las pretensiones literarias dependerá que la obra se adscriba a este subgénero, o pertenezca a la categoría de las memorias, los diarios, las biografias, las crónicas, las leyendas, las novelas costumbristas, etc.

$Y$ es que la unión de documentación y fantasía se halla en obras de todos los tiempos, desde los mismos orígenes de las culturas escritas: la escritura fue el medio para fijar los hechos que interesaba recordar a una comunidad, pero esa «verdad histórica», en sus comienzos, se tiñó de leyendas, de imaginación, de datos manifiestamente falsos... Así pues, se puede considerar que la novela histórica cuenta con antecedentes como la epopeya, la épica, las crónicas medievales, las prosificaciones de cantares de gesta, y las novelas de caballerías.

Sin embargo, lo que hoy conocemos como «novela histórica» no surge hasta finales del siglo XVIII, y no alcanza su primer momento de esplendor hasta principios del siglo XIX. Como explicó György Lukacs en su célebre estudio La novela histórica (1936), es un subgénero que se ve impulsado por la Revolución Francesa (el desarrollo de la burguesía provocó el sentimiento popular de ser parte de la Historia) y el Romanticismo (con su insatisfacción, su indagación en el pasado y el auge de los nacionalismos).

Tras las novelas dieciochescas de marco histórico y finalidad didáctica (Pedro de Montengón, El Rodrigo), el siglo XIX trajo consigo el interés por reconstruir el pasado a través de la narrativa de ficción. Y el paradigma son las obras del escocés Walter Scott (1771-1832), quien, desde el nacionalismo romántico, indagó en la Historia escocesa (Waverley, 1814) e inglesa (Ivanhoe, 1820), y encontró en ellas un refugio y un modo de reinterpretar y criticar el presente. El éxito del subgénero se hizo patente en toda la literatura finisecular occidental, tanto romántica como realista: encontramos valiosas aportaciones en Francia (Victor Hugo, Nôtre-Dame de Paris; Alexandre Dumas, Los tres mosqueteros; Gustave Flaubert, Salambô), Italia (Alessandro Manzoni, Los novios), Rusia (Alexandr Pushkin, La 
hija del capitán; Lev Tolstói, Guerra y paz), Alemania (Theodor Fontane, Antes de la tormenta), Polonia (Alexander Glowacki, Faraón; Henryk Sienkiewicz, Quo vadis?), Estados Unidos (James Fenimore Cooper, El último mohicano)... El rasgo que identifica estas obras es la presencia de un narrador, generalmente extradiegético, que construye un mundo literario en el que conviven unos «héroes medios» que acaban triunfando.

Tampoco los escritores españoles se mantuvieron al margen de esa moda: en la segunda década del siglo XIX, novelistas emigrados como Valentín Llanos y Telesforo de Trueba y Cossío escribieron sus novelas históricas en inglés; y el anónimo autor de Jicotencal publicó en Filadelfia el relato de la conquista de Hernán Cortés. Ya plenamente románticas son El doncel de don Enrique el Doliente (Mariano José de Larra), Sancho Saldaña (José de Espronceda) y El señor de Bembibre (Enrique Gil y Carrasco). Manuel Fernández González, con sus obras por entregas, representa el paso del Romanticismo al Realismo. Dentro de este último movimiento, destacan los cuarenta y seis Episodios nacionales de Benito Pérez Galdós. Y también algunos de los principales escritores del primer tercio del siglo XX contribuyeron al desarrollo de este subgénero: Pío Baroja (Memorias de un hombre de acción) y Ramón María del Valle-Inclán (con las trilogías La guerra carlista y El ruedo ibérico) son dos de los mejores ejemplos.

Con la Guerra Civil, el panorama intelectual español se empobreció, como consecuencia del exilio, la censura, la crisis editorial y la penuria generalizada. En la primera postguerra, convivieron las obras testimoniales y conformistas con la novela estilizante y la vuelta al realismo decimonónico. La contienda bélica se convirtió en foco de interés tanto de las novelas escritas por los vencedores (Agustín de Foxá, Madrid, de corte a checa, 1938; José María Gironella, con la trilogía formada por Los cipreses creen en Dios, Un millón de muertos y $\mathrm{Ha}$ estallado la paz, 1953-1966) como de las publicadas por los exiliados (Ramón J. Sender, con las nueve novelas de Crónica del alba; Arturo Barea, con las tres de La forja de un rebelde; Max Aub con las seis de El laberinto mágico; Manuel Andújar, con las tres de Visperas)... Al margen de eso, el subgénero no vivió sus mejores momentos: la actitud crítica del realismo social de los años cincuenta se centró en mostrar la cotidianidad del momento; y la experimentalidad de los sesenta y los primeros setenta se volcó más en el desarrollo formal que en la temática.

Mientras, el panorama internacional ofrecía muestras del género tan interesantes y dispares como las de Robert Graves (Yo, Claudio, 1934), Mika Waltari (Sinuhé, el egipcio, 1945) y Marguerite Yourcenar (Memorias de Adriano, 1951). $\mathrm{Y}$, en la América de habla hispana, se iban forjando la «novela del dictador» y la que Seymour Menton (La nueva novela histórica de la América Latina 1979-1992, 1993) dio en llamar «nueva novela histórica hispanoamericana», representadas 
por autores como el guatemalteco Miguel Ángel Asturias (El señor presidente, 1946), el cubano Alejo Carpentier (El siglo de las luces, 1962), el argentino Manuel Mújica Láinez (Bomarzo, 1962), el paraguayo Augusto Roa Bastos (Yo, el Supremo, 1974), el colombiano Gabriel García Márquez (El general en su laberinto, 1989), el peruano Mario Vargas Llosa (La fiesta del Chivo, 2000)... Muchos de ellos abandonaron los presupuestos instituidos por la novela histórica decimonónica para decantarse por narradores intradiegéticos que rompen con el realismo, desmitifican a los héroes, cuestionan la historia oficial, insertan anacronismos e integran lo real y lo inventado.

\section{La novela histórica española durante la transición: 1975-1982}

Durante la transición, cuatro hechos favorecen el desarrollo de la novela histórica española: el deseo de conocer el pasado desde otra perspectiva, la desaparición paulatina de la censura, la disminución de la experimentalidad en pro de la recuperación del placer de narrar, y el apogeo del género en todo el mundo. Aunque podemos rastrear esos rasgos en novelas de los últimos años del franquismo (Si te dicen que caí, 1973, de Juan Marsé), se considera que la obra que inaugura la narrativa de la transición es La verdad sobre el caso Savolta (1975), de Eduardo Mendoza. Se produce en ella una evolución desde las técnicas experimentales de los primeros capítulos (desorden cronológico, contrapunto, punto de vista múltiple) hacia la narración de una historia (una sola voz narrativa, linealidad). Además, esta novela combina los recursos de la trama policiaca con la recreación documentada de hechos históricos (la tensión social de Barcelona entre 1917 y 1919). Y sus pretensiones literarias no excluyen el uso de registros populares procedentes del folletín y la novela rosa. Toda una mezcla que conquistó a lectores y críticos, e inició una reconciliación entre el público y los novelistas españoles.

Estos últimos adquirieron la libertad de no tener que demostrar constantemente «de qué lado estaban», lo cual contribuyó a la heterogeneidad de asuntos, recursos y posturas. Sin embargo, el tema de la Guerra Civil y de sus consecuencias fue uno de los más desarrollados por la narrativa de la transición. Entre quienes lo acogieron en sus obras se encuentra Manuel Villar Raso (1936), con La Pastora, el maqui hermafrodita (1978), que narra la resistencia activa contra la dictadura; y la colección de relatos La casa del corazón (2001), que conforma una novela poética y nostálgica sobre un niño de la postguerra. Claro que, desde la recreación histórica o la testimonial, Villar Raso ha abordado también otros temas: la situación política, en Hacia el corazón de mi país (1977); el terrorismo, en Comandos vascos (1980); la aventura de los moriscos españoles en el norte de África, en Las Españas perdidas (1983); la locura de la conquista, en El último 
conquistador (1992); y la situación africana, en Donde rien las arenas (1994), El color de los sueños (1999) y La mujer de Burkina (2001).

El creciente individualismo y la variedad temática no evitaron la profusión de obras sobre un tema que la transición debía revisitar: sólo entre 1975 y 1982 , se han contabilizado más de ciento setenta novelas sobre la Guerra Civil. Casi una obsesión para los novelistas que, ya en 1978, parodiaba Juan Marsé (1933) por medio de una sátira política en la que un falangista revisaba su pasado: la metanovela La muchacha de las bragas de oro.

Se publicaron obras de política-ficción, como En el dia de hoy (1976), donde Jesús Torbado (1923) imaginó la España posterior a la victoria republicana en la guerra, a través de un relato lineal y paródico. Hubo manipulaciones de la verdad histórica, como las novelas de Carlos Rojas (1928), quien mezcló documentación, fantasía y un lenguaje depurado tanto en Mein Führer, mein Führer (1975) como en El ingenioso hidalgo y poeta Federico Garcia Lorca asciende a los infiernos (1979) y en Memorias inéditas de José Antonio Primo de Rivera (1977). Se usó la ficción para ajustar cuentas con la política del exilio: en Autobiografía de Federico Sánchez (1977) y en su continuación, Federico Sánchez se despide de ustedes (1993), Jorge Semprún (1923) narró los enfrentamientos del PCE que condujeron a la expulsión del autor. El barniz histórico ayudó a reconstruir la infancia (Asenjo Sedano, Conversación sobre la guerra, 1977). Y se recurrió al humor para abordar el franquismo, como sucede en Crónicas y milagros de Óscar Ferreira, caudillo (Gabriel Plaza Molina, 1978), y en Fábula de la ciudad (1979) y Bajo palio (1983), de Ramón Hernández (1935). También combinó humor, elementos fantásticos y temas históricos Juan Pedro Aparicio (1941): en Lo que es del César (1981), llega a la parodia macabra para plantear el embalsamamiento del cerebro del general Longuero (trasunto de Franco) con el fin de que siga mandando; en La forma de la noche (1994), aborda la Guerra Civil desde una sátira sociopolítica que combina historia, leyenda y mito; y en Qué tiempo tan feliz (2000), la indagación de la condición del escritor se produce a través de la memoria del franquismo y la democracia.

La auténtica renovación de la novela histórica española desde la muerte de Franco se produjo en la narrativa de Raúl Ruiz (1947-1987), con su amalgama de documentación, sueños, fantasía e invención libre. Los personajes intemporales de sus obras recorren la historia para crear una parodia mítica de la cultura occidental en la trilogía compuesta por El tirano de Taormina (1980), Sixto VI, relación inverosimil de un papado infinito (1981) y La peregrina y prestigiosa historia de Arnaldo de Montferrat (1984). Y varios narradores conviven en Los papeles de Flavio Alvisi (1985).

Como puede deducirse, el de novela histórica es un concepto elástico, que abarca desde obras rigurosamente documentadas hasta otras en que la recons- 
trucción de la historia es un modo de cuestionarla, de parodiarla o de tomarla como excusa para analizar el presente. Parte de la producción de Lourdes Ortiz (1943) sirve de ejemplo de esta última tendencia: Luz de la memoria (1976) reúne algunos recursos experimentales con el testimonialismo crítico al retratar el progresismo español de los últimos años del franquismo; Urraca (1982) recurre a la historia medieval para analizar las relaciones entre la mujer y el poder político; y de nuevo la presencia femenina es vital en la recreación del Imperio Romano acometida en La liberta (1999).

Del afán de reconstruir diversos momentos del pasado participaron autores como Jesús Fernández Santos (1926-1988), que noveló la Edad Media (La que no tiene nombre, 1978), los Siglos de Oro (Extramuros, 1978), la Guerra de la Independencia (Cabrera, 1981) y la etapa anterior a la Guerra Civil (Los jinetes del alba, 1984); Eduardo Alonso (1944), que narró la prisión de Quevedo para plantear el problema de la libertad (El insomnio de una noche de invierno, 1982), dio una visión humorística del franquismo (El mar inmóvil, 1981), reconstruyó satíricamente dos épocas (Los jardines de Aranjuez, 1986) y presentó el Madrid de Carlos III (La flor del jacarandá, 1991); y Carlos Pujol (1937), que reconstruyó la Roma de finales del siglo XVIII (La sombra del tiempo, 1981), se centró en la guerra carlista (Un viaje a España, 1983), y recreó la vida de una anciana añorante de la época del Imperio (El lugar del aire, 1984).

\section{La novela histórica española durante la democracia}

Hacia 1982 acaba la transición democrática: es el final de la euforia, el momento de replantearse los problemas con más objetividad. Para entonces, la vuelta a la narratividad es un hecho que convive con la incertidumbre finisecular y posmoderna, la falta de valores y las dudas en torno a «la verdad histórica». Los narradores occidentales acogen estas ideas en sus obras, y triunfan con novelas en las que los recursos del subgénero histórico se mezclan con las tramas de investigación: el éxito de las novelas de Umberto Eco es sólo uno de los paradigmas más conocidos.

Dentro de ese contexto internacional, los autores españoles continúan escribiendo, publicando, alcanzando premios y ganando lectores con novelas de tema histórico. $\mathrm{Y}$, aunque los asuntos se siguen diversificando, los de la Guerra Civil y el franquismo todavía aparecen en buen número de narraciones de muy diversos planteamientos: del realismo tradicional de Juan Benet (1927-1993) al presentar la contienda republicana en Región (Herrumbosas lanzas, 1983-85), a la postura testimonial y crítica de José Eduardo Zúñiga (1929) en los volúmenes de relatos Largo noviembre de Madrid (1980) y La tierra será un paraiso (1989), pasando por el tratamiento imaginativo de algunos escritores de la generación del medio 
siglo, como Juan Marsé (sus memorias ficticias Un dia volveré, 1982; la novela de intriga Ronda del Guinardó, 1984; y los relatos de Teniente Bravo, 1987).

Además, hay posturas irónicas, como la de Isaac Montero (1936) al mostrar la inmoralidad generada por la contienda (Pájaro en una tormenta, 1984), o al relatar la doble vida de un militar republicano durante el franquismo (Ladrón de lunas, 1998). Y la guerra se convirtió en un marco casi legendario tanto en la producción de los autores mayores (Cela, Mazurca para dos muertos, 1983) como en las de los más jóvenes: Julio Llamazares (1955), que optó por la novela sin abandonar algunas de las constantes de su poesía (la importancia del tiempo, la soledad y la memoria; y el léxico y el simbolismo del mundo campesino), en Luna de lobos (1985) se acercó a los maquis en cuatro momentos históricos.

Como Llamazares, otros representantes de lo que se denominó «el grupo leonés» optaron por la novela histórica. Así, la prosa del también poeta Luis Mateo Díez (1942) apuesta por la recuperación de tradiciones provincianas a través de personajes fracasados: recreó la vida española decimonónica en las dos novelas cortas de Apócrifo del clavel y de la espina (1977), la cotidianidad durante el franquismo en Las estaciones provinciales (1982), y el medio siglo en La fivente de la edad (1986). Por su parte, José María Merino (1941), que fue uno de los que antes usaron las técnicas experimentales para indagar en el problema de la identidad, utilizó la documentación histórica en la novela Las visiones de Lucrecia (1996), centrada en el siglo XVI. Además, es autor de la trilogía para jóvenes Crónicas mestizas (1986-88, reunidas en libro en 2002) formada por El oro de los sueños, La tierra del tiempo perdido y Las lágrimas del sol, donde seguimos las aventuras del adolescente mestizo Miguel Villacel Yölotl, hijo de un compañero de Cortés y de una indígena mexicana.

Entre los poetas que apostaron por la novela histórica en los años ochenta, cabe citar a José Antonio Gabriel y Galán (1940-1993), con El bobo ilustrado (1986) y su retrato de la época de la Guerra de la Independencia; Félix de Azúa (1944), con Mansura (1984) y su narración imaginativa de una cruzada catalana a mitad del siglo XIII, Cambio de bandera (1991) y su acercamiento a la figura del «patriota», y Momentos decisivos (2000) y su recreación de la Barcelona de los años sesenta; y Antonio Enrique (1953), autor de La armónica montaña (1986), una compleja obra simbólica y culturalista con vocación de novela total, que describe la historia de Granada y la vida del ser humano.

Gran impulsor del género fueron los premios literarios. En los años ochenta, tanto los comerciales como los de la crítica y de las instituciones se fijaron en ella: finalistas o ganadoras quedaron obras tan dispares como la primera novela de Paloma Díaz-Mas (1954), El rapto del santo Grial (1984), quien volvió a recurrir a los temas históricos en La tierra fértil (1999); la unión de historia y fantasía de Las joyas de la serpiente (1984), de Pilar Pedraza (1951), quien más tarde analiza- 
ría el siglo XVII en La fase del rubi (1987); y la recreación de la vida y la muerte del conde de Villamediana, Decidnos, ¿quién mató al conde? (1987), de Néstor Luján (1922-1995), quien volvió a centrarse en los Siglos de Oro en Por ver mi estrella Maria (1988) y La cruz en la espada (1996), y en el XVIII en Casanova o la incapacidad de perversión (1989).

Un género que se estaba convirtiendo en éxito de ventas no podía pasar inadvertido para el premio Planeta que, entre 1985 y 1988, se decantó siempre por novelas históricas. En 1985, se fijó en Juan Antonio Vallejo Nájera (1926-1990) con Yo, el rey, una fiel crónica del breve reinado de José 1 , que tiene su continuación en Yo, el intruso (1987). Un año después, premió a Terenci Moix (1943) por su relato de la antigüedad clásica y del amor de Cleopatra y Marco Antonio, No digas que fue un sueño, que constituyó un auténtico éxito editorial para un autor que volvió a los temas históricos en 1988, con Sasia la viuda y El sueño de Alejandría, y se sumergió en el Egipto faraónico con El amargo don de la belleza (1996) y El arpista ciego (2002). Tanto la novela galardonada como la finalista de 1987 fueron de tema histórico: En busca del unicornio, de Juan Eslava Galán (1948), recreaba las aventuras de un caballero medieval en África, antes de que su autor publicara otras obras de este subgénero, como Yo, Aníbal (1988), Yo, Nerón (1991), El enigma de Colón y los descubrimientos de América (1991) y Cleopatra, la serpiente del Nilo (1993); por su parte, Fernando Fernán-Gómez (1921) se acercaba por primera vez a la novela con su obra finalista en aquella edición, El mal amor, pero siguió acogiendo los temas de la historia en obras narrativas como La cruz y el lirio dorado (1998) y Capa y espada (2001). En 1988, Ricardo de la Cierva (1926) quedó finalista del Planeta con El triángulo (centrada en la época de la Guerra de la Independencia), que tuvo su continuación en El triángulo II y El triángulo III; y, en 1990, el galardón fue para la primera novela de Antonio Gala (1936), El manuscrito carmesí, donde se recrea el siglo XV a través del reinado de Boabdil.

La buena acogida del género contribuyó a que algunos escritores veteranos alcanzaran la fama durante la democracia. Así, un autor de tan larga trayectoria como José Luis Sampedro (1917) logró el reconocimiento con Octubre, octubre (1981), una novela compleja y elaborada, en que la indagación en los años anteriores a la Guerra Civil es un medio para investigar en la naturaleza humana. Más tarde, Sampedro repitió éxito de ventas con La sonrisa etrusca (1985), con la que comenzó la trilogía «Los círculos del tiempo», que se completa con una novela que recrea el Egipto del siglo III (La vieja sirena, 1990), y otra que se centra en los comienzos de la Segunda República (Real Sitio, 1993). Y también la narrativa histórica sirvió de trampolín a José Esteban (1936), autor de una novela sobre la revolución española de 1820, El himno de Riego (1984), y de otra sobre el exilio tras la Guerra de la Independencia, La España Peregrina (1985). Ambas analizan 
la proyección del pasado sobre el presente para defender la libertad: el mismo objetivo que persiguen las obras de Juan José Armas Marcelo (1946), que narró la demencia de los conquistadores españoles en Las naves quemadas (1982), y noveló los años que median entre la independencia de Cuba y el fin de la dictadura franquista, en El árbol del bien y el mal (1985).

Incluso autores veteranos plenamente consagrados optaron por indagar en la historia para construir sus novelas. Es el caso de Miguel Delibes (1920), que se acercó a la Guerra Civil con 377 A, madera de héroe (1987), y alcanzó una de sus cimas narrativas novelando sobre la inquisición y el erasmismo español en el siglo XVI, en El hereje (1998). Y es el caso también de Gonzalo Torrente Ballester (1910-1999), que con Crónica del rey pasmado (1989) se aproximó humorísticamente a la España de Felipe IV.

Conviven las obras que sirven para reflexionar y para analizar el presente con las ficciones en las que la historia es un modo de escapismo temporal, como las de Fernando Sánchez Dragó (1936): El Dorado (1984), Las fuentes del Nilo (1986) y La prueba del laberinto (1992). Hay aportaciones puntuales al género, junto a autores casi plenamente dedicados a él, como Juan Eslava Galán y Terenci Moix. Y, desde mitad de los años ochenta, Arturo Pérez-Reverte (1951) da con la fórmula para arrasar en ventas sin renunciar necesariamente a unos mínimos de calidad: la mezcla del argumento histórico con una trama policiaca y unos recursos folletinescos. Ya El húsar (1986), que se acercaba a la época de la guerra de la Independencia, y El maestro de esgrima (1988), que mostraba el ambiente político de 1868, desarrollaban esa mezcla, que empezó a ser rentable con $E l$ maestro de esgrima, y llevó a su autor a convertirse en un fenómeno editorial con La tabla de Flandes (1990), novela que fue considerada entre las mejores del año en varios países, y premiada en diversos lugares de Europa. Trufadas por incursiones en otros subgéneros narrativos, Pérez Reverte repitió la unión de aventura, intrigas y pinceladas de historia: en El club Dumas (1993), nos traslada al XVII; y en La piel del tambor (1995), construye una intriga eclesiástico-policial. Trató de homenajear la literatura de espadachines con una saga que no convenció a la crítica: El capitán Alatriste (1996), Limpieza de sangre (1997), El sol de Breda (1998) y El oro del rey (2000). La carta esférica (2000) supuso su vuelta al relato de intriga que aporta todos los ingredientes para convertirse en un superventas. $Y$ Cabo Trafagar (2004) recurre de nuevo a la historia y la acción para acercarnos a una de las más famosas derrotas españolas.

\section{La novela histórica española en el cambio de siglo}

Pasa con todos los subgéneros que alcanzan el beneplácito de los lectores: una vez las editoriales comprueban que vende, se multiplican las publicaciones 
y las colecciones, hasta que llega un punto en el que la oferta es mayor que la demanda. Entonces, decae el interés empresarial, y las editoriales se centran en otro subgénero emergente. En medio, por supuesto, se han publicado centenares de libros, y no todos son capaces de alcanzar un nivel mínimo. Pero también surgen obras que quedan en la memoria.

A pesar de la saturación del mercado, la novela histórica sigue interesando a las editoriales españolas, incluso a las que no la incluyen sistemáticamente en sus catálogos. Después del enorme éxito internacional de la obra de Dan Brown, El código Da Vinci, en la feria de Frankfurt de 2004, Seix Barral compró los derechos de El egiptólogo, en que Arthur Philips mezcla recursos policiacos con temas históricos; y de La profecia Romanov, la novela de ficción histórica en la que Steve Berry narra la lucha entre dos candidatos a ocupar el trono ruso, y las investigaciones de un abogado que acaba descubriendo la verdadera historia del asesinato del último zar. Anagrama comprometió la publicación en castellano de Omero, Iliade, la versión de La lliada del escritor italiano Alessandro Berico. Y varias editoriales anunciaron la publicación de novelas históricas de autores españoles para los próximos meses: Seix Barral Enterrad a los muertos, donde Ignacio Martínez de Pisón aborda la amistad entre John Dos Passos y su traductor español, José Robles, y la muerte de éste durante la Guerra Civil; y Tusquets Reconstrucción, donde Antonio Orejudo nos sitúa en el siglo XVI para reflexionar sobre la tolerancia y el papel de la invención de la imprenta en la difusión de herejías.

Entre los temas abordados por los novelistas españoles en el cambio de siglo, sigue destacando el de la Guerra Civil: fueron asombrosas las cifras de ventas de Javier Cercas (1962) con su novela ampliamente galardonada, Soldados de Salamina (2001), que se centra en la figura del escritor falangista Rafael Sánchez Mazas, mezclando los hechos históricos con la ficción. Puede que lo que atrajera a jurados y lectores fuera la distancia que toma el autor respecto a los hechos, que hace de la guerra un tema histórico y no uno de actualidad como, hasta cierto punto, se presentaba en las novelas anteriores a la suya.

Se llegó a hablar del «efecto Cercas» cuando se comprobó la profusión de novelas ambientadas en la Guerra Civil aparecidas tras Soldados de Salamina. Juan Antonio Bueno Álvarez (1961), que había frecuentado la novela urbana de tema contemporáneo, abordó, en El último viaje de Eliseo Guzmán (2002), el relato de tres generaciones en un pueblo de Jaén, a partir del fusilamiento del padre de Eliseo, un terrateniente arruinado constantemente enfrentado con su hijo comunista. Manuel Rico (1952), en Los dias de Eisenhower (2002), presenta a un niño de la postguerra que hace un moroso homenaje al padre vencido, con un evidente tributo a Marsé. Y Juan Carlos Arce (1958), en Los colores de la guerra (2002), plantea una novela de aventuras que se centra en la supuesta sustitución de un cuadro de Velázquez durante el traslado de los fondos del Prado en 1939. No 
obstante, hay que señalar que el dramaturgo Juan Carlos Arce se había dedicado con anterioridad a la novela histórica: presentó la época de Fernando de Rojas a través del propio autor y de sus personajes, en Melibea no quiere ser mujer (1991); y mezcló la intriga y la aventura amorosa con el relato de diversos momentos históricos: El matemático del rey (2000) refleja la pugna entre la ciencia y la Iglesia durante el reinado de Felipe IV; y La mitad de una mujer (2001) está protagonizada por un médico que trata de asesinar a Valle-Inclán en el Madrid de 1928.

Junto al policiaco ( $\mathrm{y}$, a veces, mezclado con él), el histórico sigue siendo el subgénero más fecundo entre los autores españoles, hasta el punto de que, incluso escritores tradicionalmente dedicados a otros temas, se han dedicado a novelar el pasado. Es el caso de Manuel Vázquez Montalbán (1939-2003), quien, en O César o nada (1998), abordó el paso del feudalismo a la monarquía absoluta a través de varias figuras clave del Renacimiento: Miguel Ángel, Maquiavelo, Leonardo da Vinci y otros personajes desfilan por sus páginas para mostrarnos la etapa que transcurre entre la ascensión de los sobrinos del Papa Calixto III (el valenciano Alfonso Borja) y la figura de uno de los inspiradores de la Contrarreforma, Francisco de Borja.

En los últimos años, también los historiadores han abordado el pasado desde la ficción. José Luis Corral Lafuente (1957) ubicó en la Alta Edad Media El salón dorado (1996), mezcló recursos de novela histórica y relato de intriga en El invierno de la corona. Pedro el Ceremonioso (1999), narró el fin del imperio español en la novela coral Trafalgar (2001), y presentó el mundo mediterráneo del siglo II antes de Cristo a través de la resistencia a Roma de un pueblo de Hispania en Numancia (2003). César Vidal (1958) no oculta en sus novelas de este subgénero (La mandrágora de las doce lunas, 1999; El médico de Sefarad, 2004) una ideología que hace patente también en sus ensayos y artículos. Y Alfonso Mateo-Sagasta (1960), tras su acercamiento a cuatro caballeros que nos sumergen en el mundo musulmán peninsular del año 962 (El olor de las especias, 2002), acoge la fórmula del thriller de base histórica para investigar en la figura del autor de la segunda parte apócrifa de El Quijote, en Ladrones de tinta (2004).

Y siguen las contribuciones de escritores como José Manuel Fajardo (1957), que abordó la América colombina en Carta del fin del mundo (1996), y aunó lo histórico con las aventuras en El converso (1998); Jesús Sánchez Adalid (1962), que se remontó al emirato de Córdoba del año 929 para mostrarnos sus conflictos, en El Mozárabe (2001), y presentó el enfrentamiento entre la Colonia y las Misiones jesuíticas de Paraguay, en La tierra sin mal (2003); y Miguel Ángel Pérez Oca (1943), autor de la trilogía Copernicana (Giordano Bruno, el loco de las estrellas, 2000; El libro secreto de Copérnico, 2001; Tomo, el librero, 2002), que le sirve para abogar por quienes apostaron por la libertad y la verdad científica. 
Vinculada a la abundancia de libros de viajes está la novela de peregrinos, que suele mezclar historia, aventuras y la ya clásica metáfora de la vida como viaje, del viaje iniciático. En ese territorio limítrofe se hallan las obras El camino, el peregrino y el diablo (1978), de Genaro Xavier Vallejos; Viaje a Poniente (1991), de Valentín Redín; El peregrino (1993), de Jesús Torbado; La cruz de fuego (1999), de Jaime del Burgo Torres; y lacobus (2000), de Matilde Asensi. Y es el nombre de esta última escritora el que nos lleva hasta los autores que, siguiendo el camino abierto en España por Arturo Pérez Reverte, unen en sus novelas los recursos policiacos, históricos y del relato de aventuras.

Matilde Asensi (1962), que había ganado varios premios de cuentos y novelas cortas, planteó los enigmas que sigue una anticuaria y ladrona de arte en $E l$ salón de ámbar (1999); se acercó a la Edad Media a través de la búsqueda de un tesoro poco después de la desaparición de los templarios, en lacobus (2000); y volvió a alcanzar el éxito con El último Catón (2001), donde La divina comedia (Dante) se convierte en la única herramienta para desentrañar un caso plagado de pruebas, ironía y documentación. En esa misma línea, Luis Manuel Ruiz (1973) planteó una investigación basada en los misterios de los libros y el viaje iniciático de una pareja, en Sólo una cosa no hay (2002); y volvió a hacer a otra pareja protagonista de una intriga que ahonda en los enigmas de las partituras musicales, en Obertura francesa (2002).

Además, la repercusión de El código Da Vinci parece haber jugado a favor de las novelas históricas que amalgaman aventuras y temas religiosos. Avala esta teoría el éxito de las primeras novelas de las periodistas Julia Navarro (1963), La hermandad de la sábana santa (2004), que propone un viaje desde la época de Jesucristo hasta la actualidad combinando documentación, arte e intriga; y Núria Masot (1949), La sombra del templario (2004), que nos transporta a la Barcelona de 1265 a través de una trama de misterios y muertes.

\section{El pacto con el lector}

Al terminar el franquismo, la novela española comenzó a conectar con los lectores. Escritores de varias generaciones hicieron de la libertad estética su dogma; y surgió un gran número de nuevos novelistas, a los que, en no pocas ocasiones, se acusó de aprovecharse de las nuevas leyes del mercado, de convertir la literatura en un negocio ajeno a los valores culturales. A pesar de ello, la narrativa se fue consolidando a través de las más diversas expresiones, desde el microcuento y el cuento, hasta la nouvelle y la novela larga. En terrenos limítrofes entre la ficción y la no-ficción, proliferaron los libros de viajes, las memorias, los diarios... El resultado de todo ello es un universo en el que hay serias dificultades para separar el grano de la paja, porque la mayoría de los premios distan de valorar 
la calidad, y el público lector suele hacer caso omiso de la crítica, muchas veces condicionada por la premura y los intereses de los grandes grupos editoriales.

Se ha repetido en numerosas ocasiones: la llegada de la democracia no supuso un corte en la narrativa de nuestro país. Los cambios habían comenzado ya en la última etapa franquista, gracias a autores como Juan Benet, José Manuel Caballero Bonald, Miguel Espinosa, Juan y Luis Goytisolo, Juan Marsé y Gonzalo Torrente Ballester. En el pacto con los lectores, los escritores españoles tenían, además, modelos de otras latitudes que escribían en su propia lengua: Ios novelistas del boom hispanoamericano. De la confluencia de ambos elementos han surgido obras destacadas, tanto de narradores mayores (Delibes, Martín Gaite, Matute, Sampedro, Umbral, Vázquez Montalbán...) como de quienes despuntaron en la democracia. Y, como se celebró en los años ochenta, entre esos autores había un buen número de mujeres, algunas de las cuales (Almudena Grandes, Ana María Moix, Rosa Montero, Clara Sánchez, Esther Tusquets...) han ido forjando una obra seguida y reconocida por lectores y críticos.

Nuestros novelistas han conseguido impregnar sus páginas de temas y estilos que han conquistado a sus contemporáneos. El grupo leonés (Luis Mateo Díez, José María Merino, Julio Llamazares) se encargó de demostrar que la memoria puede convertirse en un buen motor del relato. Los personajes conflictivos, desilusionados, apáticos, han poblado las producciones de escritores como Rafael Chirles, Belén Gopegui, Javier Marías y Juan José Millás. La «posmodernidad», que entró en nuestra narrativa a través de Eduardo Mendoza, Manuel Longares y, sobre todo, Jesús Ferrero, ha resultado decisiva para la profusión de novelas encasillables dentro de los subgéneros codificados: histórico, policiaco y erótico, fundamentalmente. Son diversas vías, a veces confluyentes, para obtener los mismos fines: la expresión literaria, el placer de contar historias y la complicidad con el lector. Y no cabe duda de que algunas de las novelas históricas de los últimos años (en España y en el resto del mundo) han logrado superar esas metas. Es más, en ocasiones, han alcanzado dos objetivos que tal vez ni se plantearon: difundir el conocimiento de hechos a los que el público no suele acercarse a través de la historiografia; y hacer que los lectores se cuestionen el concepto de «verdad histórica», de «interpretación del pasado» y de manipulación en general. 